\title{
Mudança na Política Externa dos Estados Latino-Americanos e Caribenhos: Uma Análise Baseada nas Votações da Assembleia Geral das Nações Unidas*
}

\author{
Ítalo Beltrão Sposito
}

Professor Adjunto na Universidade Federal do Tocantins (UFT). Palmas, Tocantins. Brasil. E-mail: italosposito@yahoo.com.br; ORCID: https:/ / orcid.org/0000-0002-2764-5744

\section{INTRODUÇÃO}

Teste artigo será discutida a literatura que utiliza votações na As1 sembleia Geral das Nações Unidas (AGNU) como variável para observar o comportamento internacional dos Estados, e as demais medidas já utilizadas como maneira de quantificar a política externa. O objetivo é analisar os avanços desta literatura para desenvolver um modelo que teste o impacto de fatores internacionais e domésticos no Redirecionamento na Política Externa (RPE) - considerado, nessa pesquisa, o grau mais extremo de mudança na política externa (MPE). Utilizarei o histórico de votações na AGNU para observar o comportamento dos países da América Latina e Caribe entre 1945 e 2008.

A literatura sobre o conceito de MPE desenvolveu diversas tipologias para diferenciar seus tipos e graus. Holsti (1982) separa mudanças de reestruturações, sendo as primeiras tipicamente graduais e setoriais, e as segundas referentes a revisões mais drásticas e abrangentes da política externa. Já Hermann (1990) desenvolveu uma escala de quatro graus: ajuste, mudança de programa, mudança de problema ou objetivo, e mudança na orientação internacional. Defende que apenas os três últimos, de caráter mais intenso, devem ser considerados MPE, enquanto o "ajuste" é algo intrínseco à política externa. Rosati (1994) também propôs uma escala de quatro graus, variando desde

\footnotetext{
* O autor agradece seus orientadores durante o doutorado, João Paulo Cândia Veiga e Janina Onuki, a Fundação de Amparo à Pesquisa do Estado de São Paulo (FAPESP) pelo apoio financeiro, os revisores anônimos da Revista DADOS pelos comentários e a atenciosa revisão editorial da revista.
}

DADOS, Rio de Janeiro, vol.62(4): e20160012, 2019. 
intensificação, a refinamento, reforma, chegando até restruturação, o tipo mais extremo.

Discutindo as características destes processos, os autores costumam considerar sua importância temporal. Enquanto as mudanças brandas são relacionadas a processos tradicionais em política externa, em que há apenas adaptação a circunstâncias internacionais ou acomodação de forças domésticas, as mais radicais seriam processos de rápida implementação (Volgy e Schwarz, 1994). Os autores apontam a importância da abrangência dos processos: os casos mais radicais devem incluir a maioria das áreas temáticas da agenda de política externa. Hogan (2006) também reitera que uma MPE deve aplicar mudanças em diversos temas da agenda de política externa.

Este artigo se atém aos casos mais extremos dentro destas tipologias, e considera necessário para serem classificadas como RPE que: a) as variações no espectro político sejam radicais/extremas; b) que sejam implementadas em curto período de tempo; e c) que abranjam diversas temáticas da agenda de política externa.

O foco do modelo será em torno da ideia de janela política, e sobre quais condições (domésticas e internacionais), aumentam as chances dos atores políticos empreenderem um processo de RPE. O conceito de janela política foi bastante utilizado pela literatura de MPE (Checkel, 1993; Doeser e Eidenfalk, 2013; Eidenfalk, 2009; Gustavsson, 1998, 1999; Hogan e Doyle, 2009; Potrafke, 2009; Walshm 2006), mas advém da literatura de políticas públicas, tendo sido criado por Kingdon (1984). O autor indica três correntes centrais para a ocorrência de RPE: reconhecimento do surgimento de um problema político, jogo político e políticas públicas. Nestes períodos, as janelas se abrem e os empreendedores políticos devem apresentar suas análises e defender sua alternativa política. Tais janelas abrem devido a mudanças no jogo político (troca de administração/governo, mais obviamente), mas também pode ocorrer após mudança nas percepções políticas.

Os autores de MPE utilizaram o conceito sem critérios preestabelecidos, e sem seguir os apontamentos de Kingdon sobre a junção das três correntes. Na literatura de MPE o conceito de janela política está relacionado a uma conjuntura política específica que pode ser iniciada tanto por uma mudança de administração, quanto por uma crise; e que tem duração curta durante a qual os atores políticos devem agir para 
inserir suas propostas na agenda. Tais conjunturas são relacionadas aos seguintes conceitos, todos, direta ou indiretamente, intrínsecos à ideia de janela política: crise econômica ou política (Gustavsson, 1999; Hay, 1999; Hogan e Doyle, 2010; Pei e Adenisk, 2000); falência ou falha política (Walsh, 2006 e Welch, 2005); conjunturas críticas (Blavoukos e Bourantonis, 2012; Cappocia e Keleman, 2007; Hogan, 2006; Soifer, 2012); mudança de regime ou do líder (Hermann, 1990; Gustavsson, 1999; Vengroff, 1976); baixo grau de institucionalização e comprometimento do governo com a política externa corrente (Hermann, 1990); disputa política doméstica em torno de temas de política externa (Clemens e Cooks, 1999); existência de contradições e baixa legitimidade na política externa (Goldmann, 1982).

Mesmo estando implícita a relação entre as condições e o conceito de janela política, não existem critérios claros para definir uma "janela política", e tampouco indicações sobre quais acontecimentos as precedem. Buscarei identificar tais condições utilizando uma amostra grande. Apesar da importância dos atores políticos nestes processos, nesse artigo não é feita a análise no plano individual, uma vez que não são disponíveis dados sobre as características individuais de todos os líderes incluídos na amostra.

Na primeira seção, discuto o uso das votações da AGNU como medida de comportamento internacional. Na segunda, apresento medidas já desenvolvidas pela literatura para capturar o comportamento internacional dos Estados, e justifico a medição escolhida. Em seguida, analiso a literatura que estuda MPE utilizando medidas quantitativas de comportamento internacional, e explico como é medida a variável dependente. Na quarta parte apresento as variáveis de interesse, o modelo estatístico, seus ajustes, os resultados, e discuto casos desviantes. Por fim, apresento as conclusões e considerações finais.

\section{A LITERATURA QUE USA VOTAÇÕES NA AGNU COMO VARIÁVEL DEPENDENTE}

Utilizando o histórico de votações na AGNU como variável dependente, a literatura de Relações Internacionais (RI) já buscou identificar os determinantes do comportamento externo dos Estados. Como variáveis explicativas, os autores apontaram o pertencimento a blocos, grupos ou regiões (Holcombe e Sobel, 1996; Kim e Russett, 1996; Lijphart, 1963; Tomlin, 1985; Russett, 1966); o oferecimento de ajuda externa - econômica ou militar - pelos Estados Unidos (EUA) (Wang, 
1999; Lai e Morey, 2006; Schaefer e Kim, 2007; Dreher e Nunnenkamp; Thiele, 2008; Moon, 1985; Ratner, 2009); empréstimos do Fundo Monetário Internacional (FMI) (Thacker, 1999; Potrafke, 2009; Carter e Stone, 2015); o grau de liberdade econômica ou política (Schaefer; Kim, 2007); a ideologia do governo (Potrake, 2009); o tipo de regime (Huxsoll, 2003; Mcgillivray e Smith, 2004; Lai e Morey, 2006); e o comércio exterior ou riqueza (Carter e Stone, 2011).

Carter e Stone (2015) dividem os autores entre aqueles que tratam votações na AGNU como índice sincero das preferências dos Estados, e aqueles que tratam como uma evidência de compra de votos. O principal argumento trazido é de que o posicionamento na AGNU não representaria posições políticas dos Estados, mas uma maneira de dar apoio político aos EUA em troca de ajuda externa. Lai e Morey (2006) também apontam que existem duas abordagens para entender o padrão de votos na AGNU: preferência de similaridades e compra de votos. A primeira examina similaridades nas preferências pelo alinhamento de votos na AGNU utilizando análise escalar e dimensional para identificar padrões de votos e coalizões (Kim e Russett, 1996; Voeten, 2000). A segunda analisa a habilidade dos Estados Unidos (e outras potências econômicas e políticas) de usar ferramentas de política externa para levar países a cooperar (Thacker, 1999; Wang, 1999).

Dreher e Jensen (2013) apontam que, apesar de ser considerada uma instituição fraca, a AGNU é um ambiente relativamente único, no qual é possível observar as posições políticas relativas de praticamente todas as nações em um mesmo arranjo institucional. Na mesma linha, Volgy e Kenski (1976) defendem que as resoluções da AGNU permitem aos países a oportunidade de registrar (ao menos simbolicamente) sua oposição à postura de seu hegemon em temas globais. Mattes, Leeds e Carroll (2015) se juntam a estes autores argumentando que as votações na AGNU são um registro de como os Estados querem ser vistos pelos demais, e das posições que cada um está disposto a tomar publicamente. Desta forma, a medida seria um indicador latente das estratégias internacionais de um país.

Assim, esta pesquisa parte do mesmo pressuposto teórico de Voeten para utilizar as votações na AGNU como variável dependente: "estes votos são indicadores manifestos do grau em que os interesses percebidos dos Estados se sobrepõem aos dos Estados Unidos" (Voeten, 2004:733-744, tradução livre). 
O mesmo não aconteceria com as votações consideradas importantes pelo departamento de Estado. Carter e Stone (2015) defendem a ideia de que o uso destas votações não é adequado para medir as preferências sinceras de um Estado, justamente por serem importantes a ponto de terem peso estratégico na arena internacional. Thacker (1999) encontra indícios da influência do apoio político aos EUA na AGNU com o recebimento de ajuda financeira via FMI.

Portanto, ao utilizar as votações na AGNU como maneira de identificar o comportamento internacional dos Estados, é necessário fazer uma importante diferenciação - tanto prática quanto teórica - entre o total dos votos e os votos considerados como importantes pelo Departamento de Estado estadunidense. Segundo informação da própria instituição, estas resoluções devem ser antecipadamente identificadas, de modo a comunicar seus aliados e países neutros de sua preocupação com o tema, informar fatos relacionados à questão, e solicitar apoio nas votações (United States, 1986).

Com base nesta diferenciação, Potrafke (2009) considera que a concordância em votações importantes teria boa repercussão junto aos EUA, enquanto as votações como um todo seriam uma medida de similaridade das preferências de um país em relação aos Estados Unidos. Comprovando isto, a análise empírica de Dreher e Jensen (2013) apontou que apenas as votações alinhadas em temas considerados importantes pelos EUA têm propensão a serem recompensadas, diferentemente do que se encontra quando utilizadas todas as votações na AGNU. Andersen, Harr e Tarp (2006) concordam que em votações importantes para o Departamento de Estado, os países tendem a votar de acordo com suas reais preferências políticas, já que não sofrem pressão dos Estados Unidos. Já Wang (1999) defende não ser relevante teorica nem substantivamente - analisar o efeito da ajuda externa sobre o total das votações na AGNU, mas somente em votações importantes, visto que para os EUA os custos em exercer pressão em todas elas seriam muito altos quando comparados aos seus ganhos marginais.

Considerando meu objetivo de observar o comportamento geral e genuíno dos Estados, e ponderada a discussão da literatura em relação às maneiras de utilizar a base de dados de votações na AGNU, julgo adequado utilizar todas as votações, em vez de focar somente nos votos considerados importantes pelo Departamento de Estado estadunidense. 


\section{MEDIDAS DE COMPORTAMENTO INTERNACIONAL DOS ESTADOS}

Para analisar o comportamento dos Estados utilizando o histórico de votações na AGNU, alguns autores utilizam o modelo espacial, que estima os pontos ideais de todos os países de acordo com seus posicionamentos sobre as resoluções levadas ao plenário. Este modelo separa modificações de agenda das alterações de preferências por meio da fixação das resoluções de um mesmo tema em sessões diferentes. Os pontos ideais podem ser interpretados como a posição dos Estados em relação à ordem liberal liderada pelos Estados Unidos na ONU. Esta medida tem as vantagens de coincidir melhor com os registros históricos, identificar de forma mais acurada mudanças nas posições dos países, e facilitar comparações intertemporais. É possível identificar a mudança de posição dos países pela identificação de 799 resoluções idênticas que são utilizadas como comparativo intertemporal - visto que em $97,2 \%$ dos casos, os países mantiveram posição nestas resoluções de mesmo tema, em anos diferentes (Bailey, Strezhnev e Voeten, 2015). Apesar dessas vantagens, não é aconselhável utilizar este tipo de estimativa como variável dependente em regressões.

Lewis e Linzer explicam que:

[...] enquanto encontramos níveis gerais de incerteza similares nas estimações geradas em cada modelo, a forma em que a incerteza da estimação é distribuída entre os membros varia consideravelmente [...] isto não deve ser surpreendente, dado que a definição do espaço temático é arbitrária e, em última estância, o que estes modelos resgatam são suas localizações relativas (2005:106, tradução do livre).

Armstrong II et al. (2014) ponderam que, por serem estimativas, as incertezas dos pontos ideais devem ser consideradas nas configurações dos modelos. Por isso, nessas estimativas não é possível tratar a variável latente para cada caso como observada, mas deve-se permitir que a incerteza presente na medida propague-se pelo modelo, variando de acordo com seu poder preditivo do modelo.

Outra possibilidade é analisar a coincidência no total de votos entre díades. Alguns autores consideram que o modo adequado para analisar a convergência política na AGNU é pela atribuição de um peso menor aos momentos em que a coincidência de voto ocorre nos 
casos de abstenção, dando um peso maior quando há coincidências em votos "sim" ou "não". No entanto, dada a possibilidade do país de ausentar-se nas votações, o voto "neutro" também pode ter um peso político e parte da estratégia de um país de não se comprometer com uma posição mais firme. Por isso alguns autores medem estritamente a coincidência de votos, ou seja, se um país se absteve de maneira idêntica aos EUA, é considerado que houve coincidência, assim como no caso de os dois terem votado positivamente ou negativamente (Dreher, Nunnenkamp e Thiele, 2008).

Por sua vez, Thacker (1999) usa um índice de concordância política que varia de 0 a 1 . Votos em concordância recebem valor 1 , em discordância 0 , e abstenções e ausências recebem o peso de 0,5 , dividindo o total pelo número de votações em determinado ano. Tal medida também é adotada por Dreher e Jensen (2013), que justificam sua utilização com razões teóricas e estatísticas. Do ponto de vista teórico, ponderam que é importante considerar as abstenções porque países podem oferecer ajuda econômica não somente em troca de apoio político, mas também para evitar potenciais atritos.

Seguindo Dreher e Jensen (2013), opto por dar meio peso às abstenções. Considerando o objetivo de identificar as preferências sinceras dos Estados na AGNU como maneira de capturar suas posições na arena internacional, pondero que esta é a melhor opção, visto que a abstenção pode representar uma posição intermediária quanto a um tema. Sua escolha, de fato, não representa concordância nem discordância com a resolução, mas uma maneira de não se posicionar sobre o tema. Sendo, portanto, um voto com peso menor. Serão usados dados da base de Bailey, Strezhnev e Voeten, (2015), mais especificamente aqueles da variável "agree3un". Esta variável computa 3 categorias de votos ("sim", "não" e "abstenção"), contanto as abstenções como meia-concordância. Serão incluídas todas as votações (não somente as importantes), visto que o objetivo é observar o comportamento geral dos Estados na política externa. Foram descartadas as votações em que algum país da díade não estava presente, visto que $68 \%$ das ausências são seguidas por outra na votação seguinte, demonstrando não representar uma posição política, mas somente a não participação de determinada delegação em uma sessão.

Por um lado, a maioria dos trabalhos que utilizam votações na AGNU como variável dependente em modelos de regressão utiliza medidas 
de coincidência, de maneira que é mais seguro se basear em uma literatura mais vasta, buscando preencher lacunas de trabalhos anteriores que trataram do mesmo tema. Quando utilizando a variável de coincidência de votos, os autores geralmente usam os Estados Unidos como país comparativo. Assim, é analisado o comportamento dos Estados latino-americanos e caribenhos em relação à postura dos Estados Unidos e seu posicionamento nas votações. Considerando-se que este artigo analisa Estados latino-americanos e caribenhos, a postura em relação aos Estados Unidos se mostra adequada, tendo em vista que a literatura tradicionalmente analisou o comportamento dos Estados da região com base na proximidade/dependência ou distanciamento/autonomia em relação à agenda internacional estadunidense. Por outro, a variável baseada no ponto ideal tem algumas vantagens já apontadas, de modo que também estimo modelos utilizando esta variável dependente, tentando observar qual captura melhor o fenômeno em foco.

A utilização desta variável também atende à definição do conceito de RPE estabelecido neste artigo. Com base nessa definição é possível observar as alterações mais radicais de comportamento dos Estados latino-americanos e caribenhos, consideradas rápidas - por podermos observar as alterações de um ano ao seguinte, pelo registro das votações nas sessões anuais da assembleia -, e por incluírem nessa arena a discussão dos temas mais relevantes da agenda internacional.

\section{A LITERATURA SOBRE MUDANÇA NA POLÍTICA EXTERNA COM BASE NAS VOTAÇÕES NA AGNU}

O objetivo é descobrir quais fatores aumentam as chances de ocorrência de uma MPE, com foco específico nos casos mais radicais (RPE). Meu interesse está nas condições conjunturais relacionadas ao que a literatura chama de janela política. É importante informar que não proponho reformular o conceito de Kingdon (1984), mas desenvolver a ideia de "janela política" nos processos de MPE.

Interessado no efeito da mudança de regime, Hagan (1989:506, tradução livre busca testar a premissa de que "revoluções políticas são o tipo primário de mudança de regime que provavelmente transformam as relações exteriores de um país" analisando 87 países do sul global entre 1946 e 1984. Para isto, propõe uma classificação gradual de cinco tipos de mudança de regime - variando desde mudança de 
chefe do Executivo sem alteração na base política do governo, até a mudança revolucionária com entrada de grupo antissistema. Busca relacioná-las com cinco gradações de orientação de votos na AGNU - variando desde fortemente pró-EUA até fortemente anti-EUA. Para calcular esta medida, o autor usou a média de coincidência de votos para cada governo e tirou sua média, separando os resultados nesta escala de cinco graus. $\mathrm{O}$ autor concluiu que transição de regime foi importante para explicar mudança de votos em metade dos casos. O alinhamento no voto ocorre em todos os tipos de mudança de regime. As mudanças não revolucionárias representam $80 \%$ das mudanças de posição em relação aos Estados Unidos, mesmo que as mudanças mais radicais na política externa tenham ocorrido após mudanças revolucionárias de regime (Hagan, 1989).

Considero que Huxsoll (2003) fez o esforço mais completo para analisar a MPE. Em sua tese de doutorado, testou nove hipóteses relacionadas ao efeito de estruturas políticas domésticas sobre a estabilidade da política externa dos Estados, utilizando um modelo de Generalized estimating equation. Apesar de ter rejeitado algumas hipóteses, Huxsoll demonstrou que as democracias têm políticas externas mais estáveis; que mudanças no Executivo aumentam chances de MPE; que a Guerra Fria está positivamente relacionada com MPE; que países desenvolvidos têm a política externa mais estável; e que sistemas multipartidários presidencialistas têm a política externa mais estável.

Mattes, Leeds e Carroll (2015) testaram o efeito de mudanças nas fontes de apoio político doméstico dos líderes sobre a política externa. O objetivo era saber se mudança na fonte de apoio do líder aumenta chances de MPE, e se as democracias são mais estáveis em comparação às autocracias. Para isto, os autores usaram o líder como unidade de análise, comparando o padrão de voto de um mandato com o de seu predecessor (estimados a partir de um modelo espacial gerado pela abordagem de simulação Markov chain Monte Carlo, com base na média de cada mandato a partir dos pontos ideais das votações em cada sessão). A partir da análise empírica, os autores defendem que em autocracias a mudança na base de apoio do líder tem efeito significativo na alteração do padrão de votações na AGNU. Tal efeito existiria também nas democracias, mas em menor grau.

Ely Ratner (2009) também desenvolveu um interessante trabalho no tema da MPE. Defendeu que as transições democráticas são importante 
causa do realinhamento junto aos Estados Unidos, condicionadas pela existência ou não de apoio da potência ao regime autocrático anterior. Um ponto que o autor levanta em seu artigo é a "direção" da MPE, atentando para a influência do apoio dos EUA: quando essa influência existe previamente, o novo regime busca se legitimar via discurso nacionalista e anti-imperialista, culpando o apoio da potência pela duração do regime anterior. Operacionalizando o nível de alinhamento político com os EUA por meio de uma variável tricotômica - alinhado, neutro, divergente - derivado do affinity of nations index, Ratner encontrou uma porcentagem muito mais baixa de aproximação política após a democratização nos casos em que o regime anterior era apoiado pelos Estados Unidos (5\% contra quase 30\% naqueles que não tiveram apoio).

Outra importante variável utilizada para explicar a MPE é a mudança de líder, cuja relação foi analisada por Dreher e Jensen (2013), utilizando um modelo de série temporal transversal para 132 países entre 1985 e 2008. Os autores investigam se a entrada de um novo líder significa alterações na política externa. Encontraram que, em média, os países se tornam mais "amigáveis" aos Estados Unidos após a entrada de um novo líder. Com base nos dados, defendem que o motivo da aproximação destes novos líderes pode resultar da busca por ajuda externa no início de um mandato.

Levando-se em conta que tais avanços no conhecimento do tema de MPE, meu objetivo é desenvolver um modelo explicativo dos processos de RPE, que são conceituados como os mais rápidos (marco temporal, considerado de um ano ao seguinte), mais radicais (maior alteração de comportamento na AGNU) e mais amplos (considerando seu comportamento geral, medido pela coincidência no total de votos na AGNU).

Pelo lado da questão temporal, as pesquisas de Hagan (1989) e Mattes, Leeds e Carroll (2015) não estudam as mudanças anuais, mas de um mandato executivo ao seguinte. Tendo em vista o objetivo de analisar mudanças mais rápidas, opto por usar como unidade de análise o país/ano.

Em relação à amplitude dos processos, serão utilizadas medidas que incluam todas as votações, garantindo observação ampla do comportamento internacional dos Estados. 
Por fim, referente à questão da radicalidade dos processos, nenhum destes autores instrumentalizou a variável dependente de modo a focar exclusivamente nesses casos. Esta diferenciação seria necessária, visto que os processos mais radicais teriam características específicas que diferem das alterações e ajustamentos comuns à política externa dos países. Por isso, defendo ser necessário moldar a variável dependente visando observar exatamente estes processos. Huxsoll (2003) e Dreher e Jensen (2013), por exemplo, usam uma variável contínua com base no padrão de votações na AGNU, não apontando haver uma diferenciação teórica entre mudanças mais radicais e pequenas alterações no alinhamento político de um ano para o seguinte (casos de "ajustes" nos rumos). Esta diferenciação é feita apenas por Ratner (2009), que usa uma variável tricotômica. Todavia, os limiares estabelecidos pelo autor são muito baixos para filtrar os casos mais radicais de MPE: abaixo de -0,15 e acima de 0,15 para os casos serem considerados de distanciamento e aproximação.

Por isso, o modelo utilizará uma variável dicotômica buscando "isolar" os casos de RPE. Para desenvolver tal medida, serão necessárias duas etapas. Primeiro, pela subtração da média de coincidência de votos do ano $t$ em relação ao ano $t-1$ será dada a medida de MPE, ou de aproximação ou distanciamento político de um ano ao seguinte - considero que quanto maior o valor deste índice, maior terá sido a MPE. Desta forma, um aumento no índice significa aproximação aos Estados Unidos, e uma queda indica distanciamento.

\section{Coincidência (ponto ideal) ${ }_{t}-$ coincidência (ponto ideal) ${ }_{t-1}=M P E$}

Segundo, com base nessa variável, será desenvolvida uma outra variável, dicotômica, em que será assinalado valor 1 para sempre que o índice MPE superar dois desvios-padrão, designando o valor nulo para os demais países/ano. Desta maneira, selecionarei os 5\% mais radicais processos de MPE, gerando a variável de RPE. Apesar da necessidade de estabelecer um limiar arbitrário, esta foi a solução prática para diferenciar processos de ajustamento na política externa dos processos de RPE, que teriam causas e efeitos diferentes tanto em termos teóricos como práticos.

As principais variáveis nos estudos anteriores foram fatores institucionais (tipos de regime político), alterações de regime ou líder, e assistência econômica por parte dos Estados Unidos. Considero 
haver duas lacunas nesses estudos anteriores: em primeiro lugar, não terem analisado a ferramenta de política externa mais radical utilizada pelos Estados Unidos para conseguir aliados: a intervenção militar. Diversos autores deram destaque ao poder de aproximação que os Estados Unidos conseguem desempenhar utilizando incentivos e punições econômicas aos governos de países em desenvolvimento, mas nenhum inclui intervenções militares diretas como variável. Em segundo, os estudos anteriores não analisaram especificamente os casos mais radicais de MPE, diferenciando-os das alterações graduais e correntes em política externa. Considero que estas são conceitualmente distintas por haver uma diferença de tipo (em contraposição à diferença em grau) nas variáveis, indicando que os casos extremos são causalmente diferentes de um ajuste padrão em política externa.

\section{DADOS E MÉTODOS}

Seguindo os trabalhos discutidos, desenvolvi um modelo que busca identificar as condições conjunturais que aumentam as chances de um ator político doméstico se engajar em um processo de RPE. Considero que tais condições conjunturais podem apresentar as características que representam uma janela política na política externa.

\section{Ajuda econômica dos EUA}

Diversos autores já analisaram os efeitos de programas de ajuda externa sobre o alinhamento político dos países em relação aos EUA, na AGNU (Wang, 1999; Schaefer e Kim, 2007; Dreher, Nunnenkamp e Thielle, 2008; Lai e Morey, 2006; Carter e Stone, 2015; Moon, 1985; Ratner, 2009). O objetivo é mensurar a influência de alterações no nível ajuda externa sobre os processos de RPE. Espero que nos anos em que os repasses financeiros são aumentados, as chances de ocorrência de processos de RPE sejam mais baixas, entendendo que o aumento nos recursos manteria a política externa de determinado país latino-americano alinhada à dos EUA.

A variável referente ao montante da ajuda dos EUA foi retirada do Green book (U.S. Overseas Loans and Grants, 2017). A variável utilizada está definida em milhões de dólares em valores constantes. 


\section{Intervenção militar}

Outra variável de origem internacional se refere à atuação dos EUA como potência hegemônica em sua principal área de influência, a América Latina. Buscando suprir uma lacuna da literatura, testo o efeito de uma intervenção armada dos EUA sobre a política externa de Estados latino-americanos e caribenhos. A expectativa é encontrar uma relação positiva entre intervenção militar e ocorrência de RPE. Os dados foram compilados para a região e período usando a base de dados International Military Intervention Data (Pearson e Baumann, 1993; Kisangani e Pickering, 2008).

A classificação da base de dados separa as intervenções entre os seguintes tipos: 1) intervenção neutra; 2) apoiar governo (inclusive restauração para abortar golpe); 3) oposição a rebeldes ou grupos de oposição; 4) opor-se ao governo; 5) apoiar rebeldes ou oposição; 6) apoiar ou opor um governo de um terceiro partido; 7) apoiar grupos rebeldes refugiados. Considerando esta classificação, separo as intervenções em dois grupos. No primeiro, incluímos os tipos (2) e (3), englobando as intervenções em que os EUA agiram para manter um regime no poder. Nesses casos, espero que não haja aumento do risco de RPE, visto que o objetivo é estabilizar o cenário político. No segundo grupo entram os tipos (4), (5), (6) e (7), que agrupam as intervenções nas quais os EUA agiram para derrubar um governo. Nesses casos, espero que aumentem os riscos de RPE.

\section{Embargo econômico}

Outra ferramenta utilizada pelos EUA é o embargo econômico. A imposição destas medidas foi historicamente utilizada para enfraquecer regimes rivais e seus líderes, e até para pressionar regimes aliados a promoverem reformas domésticas. Os dados sobre embargos econômicos foram compilados por Morgan, Bapat e Kobayashi (2014) e codificados em 15 temas na base Threat and Imposition of Sanctions (TIES) Data 4.0. Apesar de as justificativas para imposição de embargos terem variado historicamente, o objetivo sempre foi o de pressionar o governo alvo.

Por isso, utilizo a base dos autores e incluo duas medidas referentes a embargos: a) variável que identifica se em determinado ano um Es- 
tado sofreu algum tipo de embargo; nos anos em que sim, a variável recebe como valor a soma destes tipos; e b) variável diferenciada para os embargos, recebendo valor 1 quando o país é alvo de qualquer tipo de embargo, e valor - 1 sempre que este embargo acaba; a variável recebe valor nulo quando nenhum destes eventos ocorre. Espero que o número de embargos tenha o papel de estabilizar a política externa do país, visto que restringe suas opções de ação. Por outro lado, o início de um embargo teria o efeito de aumentar as chances de RPE, dado seu possível impacto desestabilizador.

\section{Regime político}

Passo agora a discutir variáveis de origem doméstica. Apesar de termos ciência de que as democracias podem ter políticas externas mais estáveis que as autocracias (Huxsoll, 2003), espero que esta influência só exista quando a variável dependente aparece como contínua, e não quando binária, como proponho. Espero que a mudança de regime tenha impacto sobre o RPE, seguindo os achados de Hagan (1989). São incluídas na análise uma classificação de seis tipos de mudança de regime: democracias parlamentares, democracias mistas, democracia presidencialista, ditadura civil, ditadura militar, ditadura monárquica (Cheibub, Gandhi e Vreeland, 2010). A mudança de regime é codificada como variáveis binária recebendo o valor 1 quando o evento ocorre. Espero que a mudança de regime tenha o efeito de aumentar as chances de RPE.

\section{Mudança de líder}

Além da mudança de regime, outra variável referente à mudança política pode ter efeito sobre o RPE: a mudança de líder. Dreher e Jensen (2013) demonstraram que novos líderes tendem a se aproximar dos EUA em busca de apoio econômico-financeiro (no entanto, tais alterações não seriam drásticas e não estariam relacionadas somente aos processos de RPE). Mais importante ainda, é que Kingdon (1984) aponta as mudanças de administração (que incluem tanto mudança de regime quanto de governo) como o exemplo mais claro de janela política. Os dados para a mudança de líder também são tirados da base dados Democracy and Dictatorship Revisited, e a variável utilizada conta quantas mudanças de chefe de Executivo de fato ocorreram em determinado ano (Cheibub, Gandhi e Vreeland, 2010). Minha expectativa é que quanto maior o 
número de mudanças no líder de fato, maiores as chances de RPE, visto que cada uma destas trocas podem ser vistas pelo novo líder como uma janela política para implementar um novo projeto de política externa.

\section{Comércio bilateral}

Visando identificar possíveis efeitos referentes ao comércio entre as díades, incluo a variável o nível de controle do comércio. Essa variável servirá mais como controle que como teste de hipótese, uma vez que não espero que o nível de comércio tenha efeito sobre as chances de RPE. Para além disso, esta também é uma variável comumente utilizada pela literatura como controle. O nível de comércio entre as díades será analisado como o superavit ou deficit na balança de pagamentos. O possível efeito seria resultar em processos de aproximação ou distanciamento político. Os dados são retirados da base Bilateral Trade também do projeto Correlates of War (Barbieri, Keshk e Pollins, 2009).

\section{Base de dados}

Os dados das bases citadas foram compilados pelo autor para analisar a interação entre as díades de 1945 a 2008. A seleção do período se deu exclusivamente pela disponibilidade de dados. Estou ciente do problema apontado por Geddes (1990) de que a seleção dos pontos finais de uma análise temporal pode afetar os resultados, mas considero que o período é longo o suficiente para que padrões gerais sejam identificados. Ademais, não é minha intenção expandir os achados para outros períodos que não o analisado.

Durante o período analisado, os Estados Unidos mantiveram sua hegemonia sobre a região tanto pela institucionalização de seu poder com a criação do Tratado Interamericano de Assistência Recíproca e da Organização de Estados Americanos, quanto pela utilização de suas ferramentas de política externa. Pastor (2001) aponta que a ajuda externa e intervenções foram utilizadas para manter aliados e estabelecer controle político sobre os países da América Latina. A pressão emanada pela potência (representada pelas três primeiras variáveis independentes apresentadas nesta seção) é considerada pela litera- 
tura como um dos principais determinantes da política externa dos países da América Latina (Below, 2017; Hey, 1997).

Foi criada uma base de dados de série de tempo transversal composta por díades de país / ano entre os EUA e todos os países da América Latina e Caribe (ao todo, 33 países). A amostra englobará países latino-americanos por três motivos. Primeiro, esta amostra foi selecionada pela disponibilidade de dados, literatura e conhecimento prévio sobre processos políticos e históricos na região (Hey, 1997). Segundo, a região apresenta especificidades nas dinâmicas geopolíticas e nos regimes políticos, resultado da influência dos EUA. Terceiro, o comportamento em relação aos Estados Unidos é um eixo de análise da política externa dos países da América Latina (Giacalone, 2012), servindo como eixo para contrapor posicionamentos anti ou pró-Estados Unidos (Hagan, 1989), anti ou pró-centro (Hey, 1997) e autônomo ou dependente (Tickner, 2015).

\section{MODELO ESTATÍSTICO}

O projeto inicial seria utilizar um modelo específico para resultado binário (recebendo valor 1 sempre que ocorresse um caso de RPE), ou logit ou probit, buscando explorar como cada variável explicativa afeta a probabilidade do resultado 1 (Long e Freese, 2001). No entanto, como a base de dados inclui série temporal e análise transversal, sigo a sugestão de Beck, Katz e Tucker (1998), de substituir o modelo de resultado binário com série de tempo por um modelo de sobrevivência. Os autores argumentam que há um problema em utilizar modelos de resultado binário para séries temporais por pressuporem independência temporal; pressuposto que, quando rompido, leva a resultados superotimistas. Para superar este problema, sugerem a utilização dos modelos de sobrevivência, nos quais o resultado positivo significa a ocorrência do evento de interesse. Esse modelo tem a vantagem de ser elaborado considerando a dependência temporal em sua especificação, calculando as taxas de risco de acontecimento do evento durante o tempo em análise.

Sendo assim, o modelo será estimado com uma função de sobrevivência que analisa o efeito das variáveis sobre as chances de ocorrência do RPE. O modelo sugerido por Beck, Katz e Tucker (1998) é o Cox Proportional Hazard Model - o mais comumente utilizado neste tipo de análise. Ele é calculado com base em uma função de risco semiparamétrica com dois componentes: (a) uma função de risco muda a partir do tempo de 
sobrevivência (período durante o qual o evento de interesse ainda não ocorreu); e (b) uma função de risco que oscila a partir das alterações nas variáveis independentes (Hosmer, Lemeshow e May, 2008).

O modelo estatístico é definido abaixo, em que: (a) $h_{0}(t)$ caracteriza como a função de risco que muda em função do tempo de sobrevivência; $(b) r(x, \beta)$ caracteriza como a função de risco muda em função dos regressores.

$$
h(t, x, \beta)=h_{0}(t) r(x, \beta)
$$

Os coeficientes são interpretados a partir de razões de risco (semelhante a razões de chances), que representam a diferença na probabilidade de ocorrência do evento quando há mudança em uma unidade na variável de interesse. O problema desse modelo é que não contém um intercepto, de forma que não é possível estimar as razões de risco para subgrupos, estimado somente o comportamento médio da amostra (Cleves, Gould e Gutierrez, 2004). Mesmo assim, o comando cluster informa sobre observações relacionadas, agrupando-as. Utilizei esta opção para identificar os 33 países da amostra.

Para determinar qual o modelo adequado para analisar os dados devemos levar em consideração a ordem dos eventos, e se há recorrência do mesmo tipo de evento (Therneau, 1996). Em relação à ordem de eventos, o modelo não inclui tal especificação, visto que RPEs não dependem de eventos anteriores. Quanto à possibilidade de recorrência do evento, esta existe no modelo, visto que um mesmo país pode passar por mais de um processo de RPE durante o período em análise.

Portanto, o modelo considera a possibilidade de eventos não ordenados do mesmo tipo, ou seja, cada um dos 33 Estados latino-americanos e caribenhos pode passar por mais de um processo de RPE (sendo este o único tipo de evento analisado) durante o período de 63 anos analisado. Foram encontradas 1.688 observações com ocorrência de 90 eventos. O evento se trata da ocorrência de um RPE, enquanto a sobrevivência é o número de anos corridos até que o evento aconteceu em determinado país. Na nomenclatura comumente utilizada por aqueles que trabalham com este tipo de modelo, a "falência" representa a ocorrência do evento e o fim da sobrevivência. Os resultados são reportados na tabela 1: 
Tabela 1

Resultados para os modelos propostos

\begin{tabular}{|c|c|c|}
\hline Variável dependente & Coincidência de votos 1 & Ponto ideal 2 \\
\hline \multirow{2}{*}{ Mudança de regime } & $3,600^{* * *}$ & $6,760^{* * *}$ \\
\hline & $(4,66)$ & $(5,41)$ \\
\hline \multirow{2}{*}{ Mudança de líder (t-1) } & $1,439^{*}$ & $1,490^{* *}$ \\
\hline & $(2,35)$ & $(2,61)$ \\
\hline \multirow{2}{*}{ Intervenção de oposição } & $5,931^{* *}$ & $7,628^{* * *}$ \\
\hline & $(2,97)$ & $(6,92)$ \\
\hline \multirow{2}{*}{ Intervenção de apoio } & 2,129 & $1,95 \mathrm{e}-14^{* * *}$ \\
\hline & $(0,74)$ & $(-74,12)$ \\
\hline $\begin{array}{c}\text { United States Agency } \\
\text { For International }\end{array}$ & 1,000 & $0,999 * * *$ \\
\hline Development (USAID) & $(0,53)$ & $(-3,43)$ \\
\hline \multirow{2}{*}{ Início de Embargo } & $3,565^{* *}$ & 1,696 \\
\hline & $(3,05)$ & $(1,41)$ \\
\hline \multirow{2}{*}{$\begin{array}{l}\text { Total de tipos de } \\
\text { Embargo }\end{array}$} & $0,157^{* * *}$ & $0,439^{* *}$ \\
\hline & $(-4,82)$ & $(-3,01)$ \\
\hline \multirow{2}{*}{ Superavit } & 1,000 & 1,000 \\
\hline & $(0,39)$ & $(0,28)$ \\
\hline $\mathrm{N}$ & 1638 & 1638 \\
\hline
\end{tabular}

Fonte: elaboração própria a partir dos resultados do modelo estatístico.

Coeficientes exponenciados; estatísticas t em parênteses

" $<<0,1^{*} \mathrm{p}<0,05,{ }^{* *} \mathrm{p}<0,01,{ }^{* * *} \mathrm{p}<0,001$

Passemos à interpretação dos resultados.

No modelo 1, a mudança de regime aumenta em 3,6 vezes os riscos de ocorrência de RPE (99,9\% de certeza). A troca de líder aumenta as chances em $43 \%$ (95\% de certeza). Nos anos em que os EUA intervêm num país opondo-se ao regime vigente, os riscos de RPE foram multiplicados 5,9 vezes ( $99 \%$ de certeza). Já o início de um embargo econômico aumenta os riscos de ocorrência de RPE em 3,5 vezes, 
mas a continuidade do embargo reverte esta tendência, diminuindo os riscos em $84 \%$. As variáveis referentes à intervenção de apoio ao regime vigente, às alterações nos repasses via United States Agency For International Development (USAID), e a mudanças na balança comercial dos países não alcançaram significância estatística.

No modelo 2, com exceção das variáveis referentes ao superavit comercial e ao início de um embargo, todas alcançaram significância estatística de 99 ou $99,9 \%$. Uma mudança de regime aumentou os riscos em 6,7 vezes. A mudança de líder no ano anterior aumenta em $49 \%$. Uma intervenção de oposição ao regime aumenta os riscos em 7,6 vezes, enquanto uma intervenção de apoio, praticamente anulou as chances de RPE. Um aumento nos repasses de um milhão de dólares diminuiu os riscos em $0,13 \%$, de modo que um corte total na média anual de repasses (US\$ 73 milhões) significaria uma queda de 9,5\% nas chances de RPE.

Os resultados mostram que as mudanças políticas domésticas cumpriram o papel de janela política. As intervenções militares também tiveram o mesmo papel, exercendo efeitos ainda mais fortes - também seguindo o esperado. Já os embargos econômicos tiveram um efeito interessante: sempre que um embargo foi imposto pelos EUA, as chances de ocorrência de RPE aumentaram, mas a continuidade do embargo diminuiu bastante os riscos, mostrando que o efeito de instabilidade ocorre somente no momento em que as medidas produzem impacto sobre a economia do país embargado.

As ferramentas econômicas de coerção, utilizadas pela superpotência para influenciar o comportamento internacional dos Estados em sua área de influência, também não tiveram um efeito tão forte quanto a intervenção militar. Por um lado, os embargos econômicos não alcançaram índices aceitáveis de significância estatística nos modelos que usam pontos ideais; por outro, as alterações nos repasses de ajuda econômica e militar pelos EUA só foram estatisticamente significantes no modelo que usa coincidência de votos. Parece plausível a hipótese de que para ter influência sobre a política externa, fatores econômicos devem impactar na esfera política. Complementarmente, a ferramenta da política externa norte-americana mais radical, a intervenção militar, tem efeito mais determinante sobre processos de RPE que as ferramentas econômicas. 
Grosso modo, apesar de algumas diferenças nos resultados, de acordo com a variável dependente utilizada, os achados seguiram o previsto na teoria.

Sigamos à análise dos ajustes dos modelos. O primeiro passo é verificar se o pressuposto de risco proporcional é violado. Podemos rejeitar a hipótese nula de que tal pressuposto foi violado, tanto para as variáveis individuais, quanto para o modelo global. O teste nos permite pressupor que a função do $\log$ da razão de risco é constante no tempo, possibilitando a generalização dos índices de risco relativos reportados nos modelos para o período analisado (1945-2008). Cleves, Gould e Gutierrez (2004) também defendem a importância do linktest que analisa se o coeficiente previsor linear quadrado é significante - ele permite verificar se a especificação de $x_{x}$ está correta, ou seja, se não há variáveis omitidas. Ambos os modelos cumprem o requisito deste teste.

Por fim, outra ferramenta para análise do ajuste do modelo é a estatística de concordância de Harrell (Harrell et al., 1982, apud Cleves, Gould e Gutierrez, 2004). No modelo 1, as variáveis independentes explicam $69 \%$ dos resultados, enquanto no modelo 2, este valor é de $71 \%$.

Finalmente, analiso os resíduos. De início, a análise gráfica:

Gráfico 1

Resíduos Cox-Snell x riscos acumulados

Modelo 1 (VD: coincidência de votos)

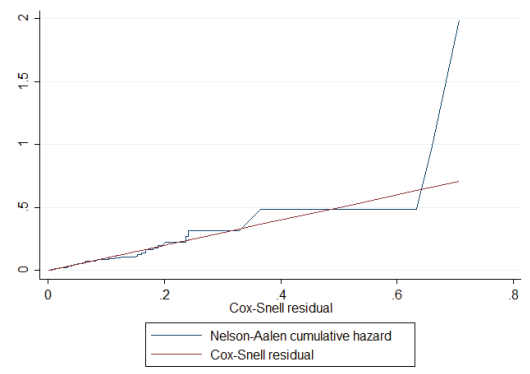

Modelo 2 (VD: ponto ideal)

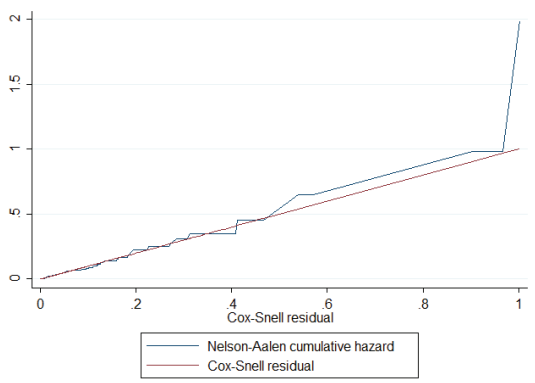

Fonte: Elaboração própria: elaboração própria a partir dos resultados do modelo estatístico.

Os gráficos apontam um ajuste satisfatório dos modelos considerando a relação entre resíduos e riscos acumulados. Nos casos com resíduos baixos, o ajuste é melhor, conforme é possível observar na sobreposição 
que representa os resíduos e aquela que representa os riscos acumulados. Com base nos resíduos, selecionei casos desviantes para análise, de modo a discutir possíveis falhas no modelo e compreender porque em determinados casos, mesmo com a ocorrência de eventos que levariam a RPE, este processo não ocorreu. Cabe mencionar que em análises quantitativas, observações individuais não podem dar apoio decisivo ou minar criticamente uma teoria (Mahoney; Goertz, 2006). As observações que apresentam altos resíduos em ambos os modelos são: 176, 180, 393, 1.175, 1.246. Elas representam, respectivamente, os seguintes países-ano: República Dominicana (1961 e 1966); Granada (1984); Suriname (1991) e Equador (2000).

\section{Casos desviantes no modelo ajustado}

\section{a) República Dominicana (1961 e 1966)}

O ano de 1961 foi marcado pelo assassinato de Rafael Trujillo, pelas forças opositoras, o com apoio da CIA - que havia dominado o comando do país desde 1930. Durante grande parte de sua ditadura, o líder teve apoio estadunidense, mas em seus últimos anos o regime sofreu com um crescente isolamento internacional. Após o assassinato de Trujillo o objetivo dos EUA passou a ser impedir que os filhos do ditador assumissem o comando do país e promovessem uma transição democrática. Para cumprir essa meta, enviou 40 navios à costa dominicana ao mesmo tempo que exerceu pressão sobre a família para que deixassem o país (Pastor, 2001).

Ramfis Trujillo retornou de Paris em $1^{\circ}$ de junho para assumir o comando do Exército e reprimir aos opositores que haviam assassinado seu pai. Manteve Joaquin Balaguer na presidência - o jurista já estava no comando da presidência desde 1960 - enquanto buscava ocupar o vazio de poder deixado por seu pai (Cidob, 2002). No entanto, temendo a continuidade de um regime da família Trujillo, os EUA alocaram oito navios e 1.080 marines na costa dominicana, pressionando pelo exílio dos familiares de Trujillo. Ao mesmo tempo, manteve Balaguer na presidência para que promovesse a transição política (Blum, 2003).

Tendo sido um amigo próximo da família Trujillo durante um longo período, Joaquin não estava tão interessado em democratizar o país. 
Assim, os EUA pressionaram sua saída após dois meses na presidência, passando o governo a um Conselho de Estado (Blum, 2003).

Considerando este caso, a intervenção militar norte-americana não teve como resultado a instalação imediata de um regime aliado ou cliente, como ocorreu em outras ocasiões. A queda do regime levou a um período mais longo de transição, que teve fim em 1962 com a eleição de Juan Bosch. O período entre a morte de Trujillo e a eleição de Bosch não foi marcado por uma mudança nas regras institucionais, no grupo no poder, ou na política externa do país - apesar da intervenção militar realizada pelos EUA e da mudança de regime. Desta forma, mesmo que o modelo preveja a ocorrência do RPE, questões específicas deste processo de transição política não levaram à ocorrência da mudança na política externa.

Em relação ao ano de 1966, a explicação é semelhante. As primeiras eleições democráticas da República Dominicana foram realizadas em 1962, um ano após a morte de Trujillo, tendo sido eleito Juan Bosch. O presidente foi deposto por um golpe militar sete meses depois. Os EUA condenaram o golpe e cortaram a ajuda econômica, mas não agiram para tentar recolocar Bosch no poder por sua tolerância a grupos de esquerda (Livingstone, 2009).

Uma junta conservadora tomou o lugar de Bosch, mas em 1965 oficiais militares progressistas se levantaram para tentar reinstalar o presidente eleito. Assim que estas forças tomaram o poder, Johnson enviou à ilha 500 marines. Dentro de um mês, 20.000 soldados estadunidenses foram mandados ao pequeno país caribenho, o que foi suficiente para derrubar os apoiadores de Bosch. Nas eleições seguintes, os EUA investiram US\$13 milhões na campanha de Joaquin Balaguer, que se tornou o novo presidente (Livingstone, 2009).

Neste caso, a intervenção norte-americana teve como objetivo conter uma contrarrevolução e impedir Bosch de retornar ao poder. Assim, a ocupação garantiu a eleição de um líder apoiado pelos EUA. O novo governo, segundo Sang, Cordero e Zeller (2000), adotou uma política externa reativa e subordinada aos interesses de Washington, em moldes bastante semelhantes à política externa do governo Trujillo. No entanto, isto não representou uma mudança com a política externa do Triunvirato militar (que governou entre dezembro de 1963 e setembro de 1965), ou do presidente Hector Garcia-Godoy Cáceres 
(presidente até agosto de 1966), que governou durante o período de transição. Todos estes atores políticos se apresentaram como agentes aliados à Washington e como versões mais moderadas do Regime Trujillo, exatamente um governo nos moldes desejados pelos EUA. Apesar da mudança de regime, não era de se esperar um processo de RPE. Portanto, não considero que este caso invalide os resultados obtidos nos modelos estatísticos.

\section{b) Suriname (1991)}

O Suriname tornou-se independente da Holanda em 1975. Durante sua história, o desenvolvimento econômico esteve atrelado à ajuda financeira repassada pela metrópole. Dessa forma, apesar da independência política formal, sua dependência econômica garantiu à Holanda um importante papel na política do Suriname, retardando seu processo de emancipação (Sedoc-Dahlberh, 1990).

A ajuda repassada pela Holanda era aplicada seguindo diretivas do Planning Bureau, instituição autônoma à política surinamesa, o que dificultava a soberania política na tomada de decisões. A falta de independência e competência política levaram a problemas econômicos, resultando na quebra da expectativa de melhora nas condições de vida da população. $\mathrm{O}$ desempenho econômico resultou em tensões sociais e disputas políticas, entre governo e Exército, sobre as diretivas nacionais e política de salários. Esse fator levou à crise política e ao golpe de Estado efetivado em 1980 pelos oficiais não comissionados do Exército, e liderados pelo Sargento-Major Desi Bouterse (Sedoc-Dahlberh, 1990).

A repressão do regime militar resultou em condenações internacionais por violação aos direitos humanos e crise de refugiados. Frente a pressão internacional, Bouterse promoveu processos de abertura. Aprovou em setembro de 1987, via referendo, uma nova constituição nacional, e criou um governo de coalizão formado pelas três principais etnias - mas ainda sob supervisão dos militares, que mantiveram poder de veto sobre as decisões parlamentares. A manutenção do poder militar ficou evidente no fim de 1990, quando o Exército removeu o governo eleito por um telefonema: Bouterse alegou que o governo havia falhado em protestar contra um insulto a ele, visto que havia sido negado seu acesso à mídia pelo governo holandês quando em trânsito no Aeroporto de Schiphol (Singh, 2008). 
A crítica ao novo golpe militar em 1990 foi unânime. A Organização dos Estados Americanos (OEA) aprovou em consenso uma resolução de repúdio ao golpe militar por atentar contra a democracia. E diante da pressão exercida por Brasil, EUA e Holanda, Bouterse agendou novas eleições para maio de 1991. Uma coalizão formada pelas principais três etnias assumiu o governo. Desta vez, com grande apoio internacional, o novo governo enfrentou os militares. Com a presença militar de tropas francesas e estadunidenses na Guiana, e norte-americanas e holandesas no Mar do Caribe, o novo governo fortaleceu-se politicamente (Singh, 2008).

O retorno ao controle civil foi marcado por iniciativas de abertura econômica. Ronald Venetiaan (1991-1996) e seu sucessor Jules Wijdenbosch (1996-2000) tomaram diversas medidas para inserir o Suriname na economia global. Além de diversas iniciativas de participação em foros multilaterais nos anos 1990, também foram adotadas medidas unilaterais de liberalização econômica. No entanto, no início da década, o processo de liberalização comercial foi limitado, devido ao esforço nacional de estabilização econômica. Os maiores progressos aconteceram somente no final da década, com a reforma substancial do sistema de licença comercial protecionista do país. Entre as principais medidas, Jessen e Katona (2001) indicam o comprometimento com medidas da Rodada Uruguai (1994), a participação como membro fundador na Organização Mundial do Comércio (OMC) (1995), ter se tornado membro ativo da agência de garantia de investimentos do Banco Mundial (MIGA) e da United States Overseas Private Investment Corporation em 1993, e a adesão ao Comunidade e Mercado Comum do Caribe (Caricom) em 1995.

Apesar da ruptura constitucional, a participação de forças internacionais garantiu a substituição do regime militar por um governo de união nacional. A pressão exercida pelas tropas internacionais garantiu um processo de transição pacífico, que deu ao novo regime a estabilidade política necessária para promover mudanças políticas de tom moderado, e de inserção controlada à economia internacional. A mudança de regime não representou a alternância entre grupos políticos opostos, como é o caso em processos de ruptura constitucional, nos quais a queda do regime ocorre após revoluções ou golpes de Estado. No campo da política externa, isso significou a adoção de um processo gradual de revisão das relações internacionais do país, que adotou na década de 1990 diversas medidas que visavam a integração do Suriname à economia global e ao modelo de regionalismo aberto. 
Apesar da expectativa de um processo de RPE, a transição pacífica para um grupo moderado garantiu uma revisão gradual da política externa do Suriname. A mudança de regime não necessariamente levou a uma alternância no poder de um grupo por outro ideologicamente oposto - o que poderia ter levado a uma completa revisão da política externa do país. Isto explica por que o modelo não explica adequadamente este caso específico.

\section{c) Granada (1984)}

Alterações nas relações internacionais de Granada se iniciam com tomada de poder pelo People's Revolucionary Army, braço armado do New Jewel Movement (NJM), em 1979. Este assalto depôs o então primeiro-ministro Eric Gairy (1967-1979) ${ }^{1}$ substituindo-o por Maurice Bishop (Boodhoo, 1985).

Desde o início do regime, as relações com Washington foram conflituosas, dada a relação de proximidade mantida entre o NJM com Cuba. Mesmo assim, relações diplomáticas entre os países foram estabelecidas no dia seguinte à tomada de poder (Boodhoo, 1985). A aproximação com o bloco socialista representava uma ameaça aos interesses dos Estados Unidos na geopolítica regional. No âmbito interno, as políticas públicas implantadas também representaram desafio ao modelo incentivado pela potência, visto que o governo Bishop promoveu reforma agrária, combateu o desemprego com ações estatais, e conferiu maior papel do Estado sobre a economia (Cotman, 2013).

Ironicamente, uma viagem de Bishop a Washington que visava estabelecer relações oficiais entre os países e atrair turistas ao país caribenho, deu início ao fim do regime. A aproximação com os EUA aumentou a fragmentação no NJM, cujos membros acusaram o líder de não ser marxista. Com seu retorno, Bishop foi mantido em prisão domiciliar, e após falha nas negociações dentro do NJM, cidadãos libertaram o líder e marcharam à Fort Rupert. Após a aparição do Exército para controlar situação, Bishop e cinco apoiadores foram executados em 13 de outubro de 1983. A resposta ocorreu em 25 de outubro, com uma invasão que contou a participação de 10 mil soldados estadunidenses, a convite da Organisation of Eastern Caribbean States (OECS) que colaborou com meros 300 soldados (Boodhoo, 1985). 
As forças estrangeiras promoveram a dissolução da junta que havia tomado o poder e conferiram o poder ao governador geral Paul Scoon, representante da Rainha Elizabeth, trazido pelos Estados Unidos e instalado como autoridade política em St. George. Os governos que participaram da invasão impuseram uma coalizão governante e criaram um Conselho Consultivo (CC), que se ocupou de desmantelar o governo revolucionário privatizando empresas nacionais, descaracterizando a economia socialista, e reestabelecendo a democracia parlamentarista (Grenade, 2015). Apesar de não ter base constitucional, tal governo se tornou legítimo pelo apoio militar e político dos Estados Unidos, que prontamente reconheceu sua autoridade legal. O Conselho desenvolveu o programa de política econômica que se tornou a base do próximo governo (Boodhoo, 1986).

Nicholas Brathwaite foi a principal figura do Conselho Consultivo Interino. O político era membro do Congresso Democrático Nacional e foi escolhido por Paul Scoon para se tornar o primeiro-ministro durante a transição. Já em dezembro de 1983 expeliu toda ajuda econômica e técnica de Cuba, e fechou programas de ajuda cubanos e a embaixada em Havana (Cotnam, 2013). O novo líder também foi responsável por nomear sete outros membros, criando um governo interino. Seu primeiro ato foi declarar Estado de Emergência, permitindo às forças invasoras deter centenas de apoiadores do NJM. Durante a ocupação, os EUA articularam uma força Interagência composta prioritariamente por agentes da USAID para inspecionar a economia. Esse grupo definiu quatro áreas para reformas domésticas: revisão dos códigos de investimento e de taxas para empresas no país; novo código trabalhista; venda de empresas públicas; e eliminação do papel do Estado no mercado de importações (Boodhoo, 1986).

Nas eleições de novembro de 1984 Herbert Blaize foi escolhido primeiro-ministro e manteve o programa econômico desenvolvido com a assistência técnica ianque, restringindo o papel do Estado na economia e garantindo direitos financeiros privados no país (Cotnam, 2013). As reformas domésticas seguiram a cartilha do livre mercado defendida pelo Governo Reagan, visando proteger direitos das empresas e encorajar investimentos privados no país, resultando na privatização da Sandino Housing Plant e na devolução de terras confiscadas pela reforma agrária (Boodhoo, 1986). 
Depois da invasão, a ajuda financeira repassada por Washington saiu do zero em 1983 para superar US\$183 milhões em 1984, montante que caiu para US $\$ 41$ milhões no ano seguinte e novamente se aproximou de zero em 1986, resultado da estabilização política na ilha e da diminuição da força política da esquerda (U.S. Overseas Loans and Grants, 2017). De acordo com a estimação do modelo estatístico, a alteração no nível de repasse de 1983 a 1984 aumentaria as chances de RPE em quase $24 \%$.

Considerando este quadro, a entrada de um regime de esquerda, com Bishop, resultou em uma política externa de aproximação a Cuba e à URSS, processo representado por um distanciamento brusco entre 1979 e 1980, e continuidade no processo de afastamento até 1983. Nesse ano, com ajuda de Washington, foi instaurado um governo interino, o que significou uma proximidade política entre o novo governo e os interesses estadunidenses. $\mathrm{O}$ novo regime agiu dentro do esperado, e promoveu reaproximação política em dois anos seguidos. Temos uma mudança de regime com resultado imediato de RPE, e o retorno de altos valores da ajuda externa oferecidos pelos Estados Unidos, garantindo a estabilização da política externa deste governo, e seu consequente alinhamento com os interesses norte-americanos.

Tendo em vista a análise histórica desenvolvida nesta subseção e os resultados do modelo estatístico, pude identificar que os altos resíduos se devem por dois fatores. Primeiro, a intervenção militar apoiada pelos Estados Unidos ocorreu em outubro de 1983, mas o impacto sobre a política externa só foi identificada na análise quantitativa no ano de 1984, apesar de algumas medidas de mudança na política externa terem ocorrido já em dezembro de 1983 (rompimento da ajuda econômica e relações diplomáticas com Cuba). Segundo, o fato de que para apoiar o novo regime os EUA aumentaram a ajuda externa, prática que na análise estatística aponta para a diminuição das chances de RPE, mas que na prática teve o efeito de aproxima a política do país da dos EUA.

\section{d) Equador (2000)}

A literatura separa a história política recente do Equador em três períodos. Após o final do regime militar, entrou em vigência a nova Constituição de 1979, e tomou posse Jaime Roldós Aguilera. Desde então, até 1996, sucederam cinco governos constitucionais, com todos 
cumprindo seus mandatos até o fim. O ano de 1996 marcou o início de um período de instabilidade política, contando com oito governos em um curto intervalo de 10 anos. Esse período se encerrou com a eleição de Rafael Corrêa em 2007, marcando o início de um novo ciclo em política doméstica e externa (Paz e Cepeda, 2009).

O período que nos interessa é o de instabilidade política, entre 1996 e 2006. Nele, três presidentes foram derrubados pelo Congresso com apoio do Exército - em 1997, 2000 e 2005 (International Crisis Group, 2007).

A desigualdade social e pobreza da maior parcela da população levou à ascensão de presidentes antissistema oriundos de novos partidos políticos, e ao retorno dos militares ao arbítrio da política. Isso legou ao enfraquecimento da regra de lei, tornando ações anticonstitucionais mais comuns (International Crisis Group, 2007).

A primeira queda foi de Abdala Bucaram, do Partido Roldosista, eleito em 1996 com 54\% dos votos. O presidente foi eleito se apresentando como um candidato antissistema e representante de movimentos sociais. Dada a falta de alcance político de sua candidatu$\mathrm{ra}$, se aliou a movimentos indígenas para vencer o segundo turno. Todavia, para conseguir governar teve que buscar apoio de partidos tradicionais, resultando em uma postura contraditória. Essa conjuntura o levou a adotar uma política econômica de austeridade fiscal com redução do Estado e privatizações, minando sua base de apoio eleitoral. Como resposta, a Confederação das Nacionalidades Indígenas Equatorianas (Conaie) se uniu a sindicatos e grupos campesinos formando o Frente Patriótico, e iniciou protestos contra sua política econômica. Diante desse cenário, o Congresso o retirou da presidência, por maioria simples, sob alegação de "incapacidade mental", evitando um complicado e longo processo de impeachment. O Exército se manteve "neutro" em relação a essa manobra (International Crisis Group, 2007).

O presidente do Congresso, Fabian Alarcón assumiu o posto de presidente interino em 11 de fevereiro de 1997. Durante os 18 meses de seu mandato, promoveu uma reforma partidária e política por meio de uma Assembleia Constituinte que promulgou uma nova constituição, e deu continuidade à política econômica ortodoxa. 
A nova constituição passou a vigorar em 1998, quando foi eleito o candidato de centro-direita Jamil Mahuad. O novo presidente se apresentou como uma esperança de retorno ao crescimento por sua competente administração durante dois mandatos na prefeitura de Quito. No entanto, além de herdar um complicado quadro de crise econômica e fiscal, Mahuad não teve competência para superar a crise. Em 1998 adotou uma série de ajustes, como a eliminação de subsídios e a adoção de políticas compensatórias, que desagradaram a população e geraram uma série de manifestações populares (Valle Jr., 2004). Dada a falta de apoio político no Congresso, o presidente governou por decretos, centralizando em si a culpa pelas medidas de ajuste econômico pouco efetivas, e pela eclosão das greves gerais que paralisaram o país em 1999. Entre agosto de 1998 e final de 1999, buscou formar cinco coalizões no Congresso, todas sem sucesso (International Crisis Group, 2007).

No início de 2000, sofrendo com a forte oposição popular e em meio a uma crise econômica, Mahuad tentou sua última cartada: a dolarização da economia. $\mathrm{O}$ anúncio da medida levou a uma revolta indígena, com apoio da população e setores do Exército. Ainda em janeiro foi criada a Junta de Salvación Nacional, formada por um militar, uma liderança indígena do Conaie e um ex-membro da Corte Suprema (Paz e Cepeda, 2009). A junta fechou o Congresso e criou o "parlamento do povo", que emitiu decreto depondo o então presidente - Mahuad abandonou o palácio após a invasão de manifestantes. No dia 22 de janeiro, o comando das forças armadas se recusou a reconhecer a legitimidade da junta, e o Congresso apontou como presidente legítimo o então vice-presidente, Gustavo Noboa, alegando abandono de cargo por Mahuad (International Crisis Group, 2007).

Noboa continuou com as políticas de inspiração neoliberal e deu seguimento à política econômica do governo anterior, implementando imediatamente a dolarização da economia, e iniciando negociações com instituições financeiras internacionais.

Dessa forma, apesar da ruptura da ordem constitucional, houve continuidade na política doméstica e internacional no Equador. A política de austeridade teve prosseguimento com Noboa, tendo sido a dolarização apoiada pelo FMI, que veio ao socorro do novo governo tão logo foi ratificada a adoção do dólar. Esta postura levou à continuidade da instabilidade política e social no país, apesar de os 
acordos terem iniciado uma recuperação da economia (International Crisis Group, 2007).

Assim, não obstante as sucessões presidenciais sem conclusão dos mandatos, o período entre 1996 e 2006 representou a continuidade de um modelo de desenvolvimento econômico que determinou o padrão de comportamento internacional equatoriano de adesão ao receituário neoliberal. Apesar dos protestos populares e da oposição dos movimentos sociais ao processo de dolarização da economia, os sucessivos governos insistiram na estratégia de liberalização econômica e comercial como tentativa de superar o problema da dívida externa e retomar o crescimento econômico e a aliança com os EUA. Mesmo com as rupturas institucionais, o Congresso, dominado pelos partidos tradicionais, se manteve como fiel da balança e garantiu a manutenção da política econômica austera, com influência determinante na política externa do país.

Este caso representou um processo em que, apesar da ruptura da ordem constitucional, deu continuidade a um modelo político e econômico de neoliberalização, e de alinhamento político aos EUA. Assim, da mesma maneira como no caso anterior, a mudança de regime não representou uma substituição completa do grupo no poder ou alteração da ordem constitucional, o que poderia ter levado a um processo de RPE. Novamente, isto explica a dificuldade do modelo em esclarecer o caso.

\section{CONSIDERAÇÕES FINAIS}

Considero que o modelo apresentou ajustes e resultados satisfatórios. As principais variáveis alcançaram índices de significância estatística altos e seguiram o previsto. As mudanças de liderança e de regime já haviam sido levantados como variáveis importantes para explicar a alteração de comportamento na AGNU, mas a literatura ainda não havia considerado o papel das intervenções militares, nem das imposições de embargos econômicos sobre os processos de MPE - apesar destas terem sido importantes ferramentas da política externa dos EUA para a América Latina.

A análise dos casos desviantes apontou para a possibilidade de existência de mudanças de regime sem alternância do grupo no poder, o 
que sublinha a importância de se discutir outras formas de analisar as RPEs para além da mudança de regime. Apesar de esses casos terem levantado questionamentos sobre a adequação teórica do modelo estatístico, um retrospecto histórico nos permitiu identificar que fatores específicos determinaram a não ocorrência de RPE, conferindo maior robustez aos resultados.

Ademais, a instrumentalização da variável dependente segundo os critérios apresentados, seguindo a relação entre a teoria e dados disponíveis, significou o isolamento do fenômeno em voga neste artigo, possibilitando estabelecer relações diretas entre as condições do ambiente e os processos de RPE.

(Recebido para publicação em 18 de janeiro de 2016)

(Reapresentado em 8 de junho de 2019)

(Aprovado para publicação em 13 de junho de 2019)

\section{NOTA}

1. Eric Gairy foi premier, no período anterior à independência de Granada (1967-1974), e primeiro-ministro após sua independência (1974-1979). 


\section{REFERÊNCIAS BIBLIOGRÁFICAS}

ANDERSEN, Thomas Barnebeck; HARR, Thomas; TARP, Finn. (2006), “On US politics and IMF lending". European Economic Review, v. 50, n. 7, pp. 1843-1862.

ARMSTRONG II, David A. et al. (2014), Analyzing spatial models of choice and judgment with R. Boca Raton, FL: CRC Press, Taylor \& Francis Groupp.

BAILEY, Michael A.; STREZHNEV, Anton; VOETEN, Erik. (2015), “Estimating dynamic state preferences from United Nations Voting Data". Journal of Conflict Resolution, v. 61, n. 2, pp. 430-456.

BARBIERI, Katherine; KESHK, Omar M.G.; POLLINS, Brian M. (2009), “Trading data: evaluating our assumptions and coding rules". Conflict Management and Peace Science, v. 26, n. 5, pp. 471-491.

CIBOD (BARCELONA CENTRE FOR INTERNATIONAL AFFAIRS) (2002), "Joaquín Balaguer Ricador, Biografías de Líderes Políticos (República Dominicana)”. Barcelona Centre for International Affairs [online]. Disponível em: https://www.cidob.org/ biografias_lideres_politicos/america_central_y_caribe/republica_dominicana / joaquin_balaguer_ricardo. Acessado em: 4 de outubro de 2019.

BECK, Nathaniel; KATZ, Jonathan N.; TUCKER, Richard. (1998), “Taking time seriously: time-series-cross-section analysis with a binary dependent variable". American Journal of Political Science, v. 42, n. 4, pp. 1260-1288.

BELOW, Amy. (2010), "Latin American Foreign Policy". International Studies Encyclopedia. International Studies Association Compendium Project. Hoboken: Wiley-Blackwell Publishers, pp. 4806-4825.

(2017), "Latin American Foreign Policy". Oxford Research Encyclopedia of InternationalStudies[online].Disponívelem:https://oxfordre.com/internationalstudies /view/10.1093/acrefore/9780190846626.001.0001/acrefore-9780190846626-e-253. Acessado em 9 de novembro de 2019.

BLAVOUKOS, Spyros; BOURANTONIS, Dimitris. (2012), "Policy entrepreneurs and foreign policy change: the greek-turkish rapprochement in the 1990s". Government and Opposition, v. 47, n. 4, pp. 597-617.

BLUM, William. (2003), Killing hope: U.S. military and CIA interventions since World War II. London: Zed Books.

BOODHOO, Ken. (1985), "Revolutionary Grenada and the United States" (Dialogue \#48). LACC Occasional papers series. Dialogues (1980 - 1994). Disponível em: http://digitalcommons.fiu.edu/laccopsd/48. Acessado em 4 de outubro de 2019.

. (1986), "The grenada revolution: rationale for failure and lessons for the Caribbean" (Dialogue \#61). LACC Occasional papers series. Dialogues (1980-1994). Disponível em: http://digitalcommons.fiu.edu/laccopsd/8. Acessado em 4 de outubro de 2019.

CARTER, David B.; STONE, Randall W. (2015), "Democracy and multilateralism: the case of vote buying in the un general assembly". International Organization, v. 69, n. 01, pp. 1-33.

CHECKEL, Jeff. (1993), “Ideas, Institutions, and the Gorbachev Foreign Policy Revolution”. World Politics, v. 45, n. 2, pp. 271-300. 


\section{Ítalo Beltrão Sposito}

CHEIBUB, José Antonio; GANDHI, Jennifer; VREELAND, James Raymond. (2010), "Democracy and dictatorship revisited". Public Choice, v. 143, n. 1-2, pp. 67-101.

CLEMENS, Elisabeth S.; COOK, James M. (1999), "Politics and institutionalism: explaining durability and change". Annual Review of Sociology, v. 25, n. 1, pp. 441-466.

CLEVES, Mario Alberto; GOULD, William W.; GUTIERREZ, Roberto G. (2004), An introduction to survival analysis using stata. Rev. ed. College Station, Tex: Stata Press.

COTMAN, John Walton. (2013), "Coming in from the Cold: Grenada and Cuba since 1983". (2013), The Round Table, v. 102, n. 2, pp. 155-165.

DOESER, Fredrik; EIDENFALK, Joakim. (2013), “The importance of windows of opportunity for foreign policy change". International Area Studies Review, v. 16, n. 4, pp. 390-406.

DREHER, Axel; JENSEN, Nathan M. (2013), “Country or leader? Political change and UN General Assembly voting". European Journal of Political Economy, v. 29, pp. 183-196.

DREHER, Axel; NUNNENKAMP, Peter; THIELE, Rainer. (2008), “Does US Aid Buy UNGeneral Assembly Votes? A Disaggregated Analysis". Public Choice, v. 136, n. 1/2, pp. 139-164.

EIDENFALK, Joakim. (2009), A window of opportunity? Australian foreign policy change towards East Timor 1998-99 and Solomon Islands 2002. 355 f. Tese (Doutorado em Filosofia), University of Wollongong, Wollongong.

GEDDES, Barbara. (1990), "How the cases you choose affect the answers you get: selection bias in comparative politics". Political Analysis, v. 2, pp. 131-150.

GIACALONE, Rita. (2012), "Latin American foreign policy analysis: external influences and internal circumstances". Foreign Policy Analysis, v. 8, n. 4, pp. 335-354.

GOLDMANN, Kjell. (1982), “Change and stability in foreign policy: detente as a problem of stabilization". World Politics, v. 32, n. 2, pp. 230-266.

GRENADE, Wendy C. (2015), The Grenada Revolution: reflections and lessons. Jackson: University Press of Mississippi.

GUSTAVSSON, Jakob. (1999), "How should we study foreign policy change?" Cooperation and Conflict, v. 34, n. 1, pp. 73-95.

. (1998), The politics of foreign policy change: explaining the Swedish reorientation on EC membershipp. Lund: Lund University Press.

HAGAN, Joe D. (1989), "Domestic political regime changes and Third World voting realignments in the United Nations, 1946-84". International Organization, v. 43, n. 3, pp. 505.

HAY, Colin. (1999), "Crisis and the structural transformation of the state: interrogating the process of change". The British Journal of Politics and International Relations, v. 1, n. 3, pp. 317-344.

HEY, Jeanne A. K. (1997), "Three building blocks of a theory of Latin American Foreign Policy". Third World Quarterly, v. 18, n. 4, p. 631-657.

HERMANN, Charles F. (1990), “Changing course: when governments choose to redirect foreign policy". International Studies Quarterly, v. 34, n. 1, pp. 3-21.

HOGAN, John. (2006), "Remoulding the critical junctures approach". Canadian Journal of Political Science/Revue Canadienne de Science Politique, v. 39, n. 3, pp. 657-679.

DADOS, Rio de Janeiro, vol.62(4): e20160012, 2019. 
HOGAN, John; DOYLE, David. (2009), "A comparative framework: How broadly applicable is a 'rigorous' critical junctures framework?" Acta Politica, v. 44, n. 2, pp. 211-240.

(2010), "A revised critical juncture framework: privatisation policy in Brazil and Argentina". Asian Journal of Latin American Studies, v. 23, n. 3, pp. 67-110.

HOLCOMBE, Randall G.; SOBEL, Russell S. (1996), "The stability of international coalitions in United Nations voting from 1946 to 1973". Public Choice, v. 86, n. 1-2, pp. 17-34.

HOLSTI, Kalevi J. (1982), Why nations realign: foreign policy restructuring in the postwar world. London: Allen and Unwin.

HOSMER, David W.; LEMESHOW, Stanley; MAY, Susanne. (2018), Applied Survival Analysis: Regression Modeling of Time-to-Event Data. Hoboken: John Wiley \& Sons, Inc.

HUXSOLL, David B. (2003), Regimes, institutions and foreign policy change. 2003. $239 \mathrm{f}$. Tese (Doutorado em Ciência Política) Louisiana State University, Baton Rouge.

INTERNATIONAL CRISIS GROUP. (2007), “Ecuador: overcoming instability?" Latin American Report, n. 22, pp. 1-32.

JESSEN, Anneke; KATONA, Andrew. (2001), "Breaking from isolation: Suriname's participation in regional integration initiatives". Occasional Paper 10. Buenos Aires: InterAmerican Development Bank.

KIM, Soo Yeon; RUSSETT, Bruce. (1996), "The new politics of voting alignments in the United Nations General Assembly". International Organization, v. 50, n. 04, pp. 629.

KINGDON, John W. (1984), Agendas, alternatives, and public policies. Boston, Mass: Little, Brown and Co.

KISANGANI, Emizet F.; PICKERING, Jeffrey. (2008), International Military Intervention, 1989-2005: Version 1. ICPSR - Interuniversity Consortium for Political and Social Research. Disponível em: http://www.icpsr.umich.edu/icpsrweb/ICPSR/studies/21282/version/1. Acessado em 4 de outubro de 2019.

LAI, Brian; MOREY, Daniel S. (2006), "Impact of regime type on the influence of U.S. Foreign Aid". Foreign Policy Analysis, v. 2, n. 4, pp. 385-404.

LEWIS, Jeffrey B.; LINZER, Drew A. (2005), "Estimating regression models in which the dependent variable is based on estimates". Political Analysis, v. 13, n. 04, pp. 345-364.

LIJPHART, Arend. (1963), "The analysis of bloc voting in the General Assembly: a critique and a proposal". American Political Science Review, v. 57, n. 04, pp. 902-917.

LIVINGSTONE, Grace. (2009), America's backyard: the United States and Latin America from the Monroe Doctrine to the War on Terror. London, New York: Zed Books.

LONG, J. Scott; FREESE, Jeremy. (2001), Regression models for categorical dependent variables using Stata. College Station, Tex: Stata Press.

MATTES, Michaela; LEEDS, Brett Ashley; CARROLL, Royce. (2015), “Leadership turnover and foreign policy change: societal interests, domestic institutions, and voting in the United Nations". International Studies Quarterly, v. 59, n. 2, pp. 280-290.

MCGILLIVRAY, Fiona; SMITH, Alastair. (2004), “The Impact of Leadership Turnover on Trading Relations Between States". International Organization, v. 58, n. 03, pp. 567-600. 


\section{Ítalo Beltrão Sposito}

MOON, Bruce E. (1985), "Consensus or compliance? Foreign-policy change and external dependence". International Organization, v. 39, n. 2, pp. 297-329.

MORGAN, T. Clifton; BAPAT, Navin; KOBAYASHI, Yoshi. (2014), "The threat and imposition of sanctions: updating the TIES dataset". Conflict Management and Peace Science, v. 31, n. 5, pp. 541-558.

PASTOR, Robert A. (2001), Exiting the whirlpool: U.S. foreign policy toward Latin America and the Caribbean. 2a. ed. Boulder, Colo: Westview Press.

PAZ, Juan J.; CEPEDA, Miño. (2009), “Ecuador en la Globalización: 1975-2005". Historia Actual Online, n. 18, pp. 25-39.

PEARSON, Frederic S.; BAUMANN, Robert A. (1993), International Military Intervention, 1946-1988: Version 1. ICPSR - Interuniversity Consortium for Political and Social Research. Disponível em: http://www.icpsr.umich.edu/icpsrweb/ICPSR/studies/6035/version/1. Acessado em 4 de outubro de 2019.

PEI, Minxin; ADESNIK, Ariel David. (2000), “Why recessions don't start revolutions”. Foreign Policy, n. 118, pp. 138-151.

POTRAFKE, Niklas. (2009), "Does government ideology influence political alignment with the U.S.? An empirical analysis of voting in the UN General Assembly". The Review of International Organizations, v. 4, n. 3, pp. 245-268.

RATNER, Ely. (2009), "Reaping what you sow: democratic transitions and foreign policy realignment". Journal of Conflict Resolution, v. 53, n. 3, pp. 390-418.

ROSATI, Jerel A. (1994), "Cycles in foreign policy restructuring: the politics of continuity and change in U.S". In: J. A. Rosati; J. D. Hagan; M. W. Sampson (eds.). Foreign policy restructuring: how governments respond to global change. Studies in international relations. Columbia, Univ. of South Carolina Press, pp. 221-261.

RUSSETT, Bruce M. (1966), "Discovering voting groups in the United Nations". American Political Science Review, v. 60, n. 2, pp. 327-339.

SANG, Mu-Kien Adriana; CORDERO, Walter; ZELLER, Neici. (2000), La política exterior dominicana, 1844-1961. Santo Domingo, República Dominicana: Secretaría de Estado de Relaciones Exteriores.

SCHAEFER, Brett D.; KIM, Anthony B. (2007), U.S. aid does not build support at the U.N. Backgrounder, n. 2018, pp. 1-13.

SEDOC-DAHLBERG, Betty Nelly. (1990), “Domestic and foreign policy under military and civilian rule". In: B. N. Sedoc-Dahlberg (ed.), The Dutch Caribbean: prospects for democracy. New York: Gordon and Breach. pp. 17-34.

SINGH, Chaitram. (2008), "Re-democratization in Guyana and Suriname: Critical Comparisons". European Review of Latin American and Caribbean Studies I Revista Europea de Estudios Latinoamericanos y del Caribe, n. 84, pp. 71-85.

SOIFER, Hillel David. (2012), "The causal logic of critical junctures". Comparative Political Studies, v. 45, n. 12, pp. 1572-1597.

THACKER, Strom C. (1999), “The high politics of IMF Lending”. World Politics, v. 52, n. 1, pp. 38-75. 
THERNEAU, Terry M. (1996), "Extending the Cox model”. Technical Report Number 58. Department of Health Science Research, Mayo Clinic.

TICKNER, Arlene B. (2015), “Autonomy and Latin American International Relations Thinking". In: J. I. Domínguez; A. Covarrubias Velasco, A. (eds.), Routledge handbook of Latin America in the world. Routledge international handbooks. New York, London: Routledge, Taylor \& Francis Group, pp. 74-84.

TOMLIN, Brian W. (1985), "Measurement validation: lessons from the use and misuse of UN General Assembly roll-call votes". International Organization, v. 39, n. 1, pp. 189-206.

UNITED STATES. (1986), Report to Congress on Voting Practices in the United Nations During 1985. Washington: Department of State.

UNITED STATES AGENCY FOR INTERNATIONAL DEVELOPMENT (USAID). (2017), U.S. Overseas Loans and Grants: Obligations and Loan Authorizations, July 1, 1945-September 30, 2017. Disponível em: https://www.usaid.gov/developer/greenbookapi. Acessado em 4 de outubro de 2019.

VALLE JR., Raul David do. (2004), "Equador: O áspero caminho das obragens à ALCA". In: H. V. de Araujo (ed.), Os países da comunidade andina. Brasília: Fundação Alexandre de Gusmão/Instituto de Pesquisa de Relações Internacionais, v. 2. pp. 743-828.

VENGROFF, Richard. (1976), "Instability and Foreign Policy Behavior: Black Africa in the U.N." American Journal of Political Science, v. 20, n. 3, pp. 425-438.

VOETEN, Erik. (2000), "Clashes in the Assembly". International Organization, v. 54, n. 2, pp. $185-215$.

. (2004), “United Nations to U.S. Dominance". The Journal of Politics, v. 66, n. 3, pp. 729-754.

VOLGY, Thomas J.; KENSKI, Henry C. (1976), "Toward an exploration of comparative foreign policy distance between the United States and Latin America. A research note". International Studies Quarterly, v. 20, n. 1, pp. 143-166.

VOLGY, Thomas J.; SCHWARZ, John E. (1994), "Foreign policy restructuring and the myriad webs of restraint: some conceptual and theoretical issues". In: J. A. Rosati; J. D. Hagan; M. W. Sampson (eds.), Foreign policy restructuring: how governments respond to global change. Columbia: Univ. of South Carolina Press, pp. 23-24.

WALSH, James I. (2006), "Policy failure and policy change: british security policy after the Cold War". Comparative Political Studies, v. 39, n. 4, pp. 490-518, Mai 2006.

WANG, Tian Yong. (1999), "U.S. Foreign Aid and UN Voting: an analysis of important issues". International Studies Quarterly, v. 43, n. 1, pp. 199-210.

WELCH, David A. (2005), Painful choices: a theory of foreign policy change. Princeton: Princeton Univ. Press. 


\section{RESUMO}

Mudança na Politica Externa dos Estados Latino-Americanos e Caribenhos: Uma Análise Baseada nas Votações da Assembleia Geral das Nações Unidas

Neste artigo buscamos encontrar as principais condições conjunturais que podem aumentar as chances de Redirecionamentos na Política Externa (RPE), com base na análise de países latino-americanos entre 1945 e 2008. O objetivo é testar o efeito de variáveis identificadas com o conceito de "janela política", utilizado pela literatura para definir os melhores períodos para os tomadores de decisões iniciarem processos de RPE. Para isso, utilizamos um modelo de sobrevivência (Cox Proportional Hazard Model) que analisa o efeito das variáveis sobre as chances de ocorrência de um evento, o RPE. A variável dependente se baseia na coincidência de votos entre os Estados Unidos e cada país latino-americano, e no ponto ideal destes países nas sessões anuais da Assembleia Geral das Nações Unidas. É considerada como ocorrência de RPE uma alteração anual superior a dois desvios padrões. As variáveis de interesse são: mudança de regime, mudança de líder, intervenção militar dos Estados Unidos, alteração no nível de ajuda financeira repassada, e imposição de embargos econômicos pelos EUA.

Palavras-chave: redirecionamento; política externa; janela política; Assembleia Geral das Nações Unidas; Cox Proportional Hhazard Model

\section{ABSTRACT \\ Changes in Foreign Policies of Latin American and Caribbean States: An Analysis Based on the United Nations General Assembly Voting Records}

In this article, we seek to find the main conjuncture conditions that may increase the chances of Foreign Policy Redirections, based on an analysis of Latin American countries between 1945 and 2008. The goal is to test the effect of variables identified with the concept of "policy window", used in the literature to define the best periods for decision-makers to initiate foreign policy redirection processes. In order to do so, we used a survival model (Cox Proportional Hazard Model) that analyzes the effect of variables on the chances of an event occurring, in this case, the foreign policy redirections. The dependent variable is based on the coincidence of votes between the United States and each Latin American country, and the ideal point of these countries at the annual sessions of the United Nations General Assembly. Foreign policy redirection is considered to occur when there is an annual change greater than two standard deviations. Variables of interest are: regime change, change of leader, US military intervention, change in the level of financial aid, and US imposition of economic embargoes. 
Keywords: redirection; foreign policy; policy window; United Nations General Assembly; Cox Proportional Hazard Model

\section{RÉSUMÉ}

Changement de Politique Étrangère dans les Pays d>Amérique Latine et des Caraïbes: Une Analyse Basée sur les Votes de l>Assemblée Générale des Nations Unies

Dans cet article, on cherche à trouver les principales conditions de conjoncture susceptibles d'accroître les chances de réorientation de la politique étrangère (RPE), sur la base de l>analyse des pays d>Amérique Latine entre 1945 et 2008. L〉objectif est de tester l`effet des variables identifiées par le concept de «fenêtre politique», utilisée dans la littérature pour définir le meilleur moment pour que les décideurs lancent les processus de RPE. Pour cela, on a utilisé un modèle de survie (Cox Proportional Hazard Model) analysant l'effet des variables sur les chances de survenue d'un événement, le RPE. La variable dépendante est basée sur la coïncidence des votes entre les États-Unis et chaque pays d`Amérique Latine et sur le point idéal de ces pays lors des sessions annuelles de l>Assemblée Générale des Nations Unies. Un changement de RPE est considéré comme un changement annuel supérieur à deux écarts types. Les variables dintérêt sont: le changement de régime, le changement de dirigeant, l>intervention militaire américaine, l>évolution du niveau de l>aide financière transférée et les embargos économiques américains.

Mots-clés: forwarding, politique étrangère; fenêtre politique; Assemblée Générale des Nations Unies; Cox Proportional Hazard Model

\section{RESUMEN}

Cambio en la Politica Exterior de los Estados Latinoamericanos y Caribeños: Un Análisis Basado en las Votaciones de la Asamblea General de las Naciones Unidas

En este artículo buscamos encontrar las principales condiciones coyunturales que pueden aumentar las oportunidades de Reordenamientos de la Política Exterior (RPE), con base en el análisis de países latinoamericanos entre 1945 y 2008. El objetivo es probar el efecto de variables identificadas con el concepto de "ventana política", utilizado por la literatura para definir los mejores períodos para que los tomadores de decisiones inicien procesos de RPE. Para eso, utilizamos un modelo de sobrevivencia (Cox Proportional Hazard Model) que analiza el efecto de las variables sobre las oportunidades de ocurrencia de un evento, el RPE. La variable dependiente se basa en la coincidencia de votos entre los Estados Unidos y cada país latinoamericano y en el punto ideal de estos países en las sesiones anuales de la Asamblea General de las Naciones Unidas. Se considera como ocurrencia de RPE una alteración anual superior a dos desvíos típicos. Las variables de interés son: 
Ítalo Beltrão Sposito

cambio de régimen, cambio de líder, intervención militar de los Estados Unidos, alteración en el nivel de ayuda financiera repasada, e imposición de embargos económicos por los EUA.

Palabras clave: reordenamiento; política exterior; ventana política; Asamblea General de las Naciones Unidas; Cox Proportional Hhazard Model 